\title{
La estratificación socioeconómica como proceso biopolítico: divisiones sociales y raciales y sus representaciones en Los estratos de Juan Cárdenas
}

Angie Carolina Mojica Sánchez / Universidad de los Andes

\begin{abstract}
El pensamiento occidental moderno es un pensamiento abismal. Éste consiste en un sistema de distinciones visibles e invisibles, las invisibles constituyen el fundamento de las visibles. Las distinciones invisibles son establecidas a través de lineas radicales que dividen la realidad social en dos universos, el universo de "este lado de la línea" y el universo del "otro lado de la línea". La división es tal que "el otro lado de la línea" desaparece como realidad, se convierte en no existente, y de hecho es producido como no existente.
\end{abstract}

Boaventura de Sousa Santos, Para descolonizar a Occidente: más allá del pensamiento abismal (12).

En Colombia no resulta extraña la idea de que las personas pertenecen a un estrato social determinado cuyo valor numérico se ubica en una escala del 1 al 6. Dicha estratificación no es el producto de una creación colectiva fortuita y, en sentido estricto, no se refiere a las personas sino a las viviendas, pues son estas últimas las que se clasifican en la escala según sus condiciones de infraestructura. Esta clasificación numérica, amparada bajo la nomenclatura de estrato, proviene de una política pública reglamentada en 1994 con un objetivo esencial: establecer un cobro diferencial en el pago de servicios públicos domiciliarios (SPD) a través de la asignación de subsidios para las personas con menor capacidad de pago. Sin embargo, los efectos de la implementación de dicha política desbordan esta intención primigenia y configuran segmentaciones sociales enmarcadas en una segregación que no sólo es espacial, sino también social y racial.

En ese orden de ideas, este ensayo analiza la política pública de estratificación socioeconómica para demostrar que es un proceso de carácter biopolítico y subrayar las divisiones sociales y raciales correlacionadas con su instauración. La primera sección contiene un estudio de las disposiciones normativas sobre la estratificación, el cual toma en consideración el contexto en el que emerge esta política y los tópicos principales de discusiones sostenidas respecto a su eficacia. Así, se presenta un análisis necesario para comprender de qué manera se relaciona la política de estratificación socioeconómica con la novela Los estratos (2013), escrita por Juan Cárdenas. La biopolítica se configura como un marco de análisis transversal de este primer apartado cuyos conceptos e ideas centrales se retoman especialmente de los planteamientos foucaultianos. La segunda sección hace hincapié en las divisiones sociales y raciales, relacionadas con la estratificación, que acentúan la segregación y que tienen injerencia en las formas como se piensan las diferencias. A partir de lo anterior, se examina la configuración de las segregaciones en la obra de Cárdenas mencionada previamente. La sección final recoge los apuntes sobre la estratificación como proceso biopolítico, su interrelación con las divisiones sociales y raciales, y la segregación como insumo pertinente para el análisis de Los estratos. Allí, se propone una exégesis de esta obra mediante la cual se desplazan deliberadamente los aspectos adheridos a la interpretación de la misma en los que subyace una perspectiva de corte psicológico.

\section{La estratificación socioeconómica: hacer vivir}

Una política pública es un "conjunto de acciones implementadas en el marco de planes y programas gubernamentales diseñados por ejercicios analíticos de algún grado de formalidad, en donde el conocimiento aunado a la voluntad política y los recursos disponibles viabilizan el logro de objetivos sociales" (Ordónez-Matamoros 2013, 31). En ese sentido, una ley per se no es una política pública, pues para que pueda ser considerada como tal, debe estar correlacionada con un conglomerado de actividades específicas. Además, las políticas públicas también son "instituciones creadas por estructuras de poder y se imponen como directrices para abordar las prioridades de la agenda pública" (Eslava 2011, 33) y buscan la solución de un problema particular en el marco de una coyuntura específica. De acuerdo con lo anterior, sin duda la estratificación socioeconómica es una política pública en tanto estipula procedimientos y acciones específicas que tienen injerencia en la esfera de lo público. La estratificación nace de disposiciones gubernamentales que, a primera vista, pretenden dar solución a un problema social: la falta de acceso a servicios públicos por parte de algunos sectores específicos de la población. Con lo anterior en mente, el análisis de esta sección se edifica a través del estudio de las disposiciones normativas sobre la estratificación e intenta vincular 
grosso modo aspectos del contexto en el que surge dicha política y las implicaciones de sus acciones en términos sociales, integrados a la exégesis de la novela Los estratos.

Para comenzar, es importante subrayar que la Constitución Política de Colombia del año 1991 promulga que "el bienestar general y el mejoramiento de la calidad de vida de la población son finalidades sociales del Estado. Será objetivo fundamental de su actividad la solución de las necesidades insatisfechas de salud, de educación, de saneamiento ambiental y de agua potable" (art. 366). La Ley 142 de 1994, en la que se establece el Régimen de los Servicios Públicos Domiciliarios (SPD), comulga plenamente con dicha directriz; allí se propende por la creación de mecanismos para la solución de necesidades insatisfechas respecto al acceso a los SPD y es precisamente de ella de donde emana la política pública de estratificación.

En síntesis, dicha ley estipula las disposiciones concernientes al funcionamiento de un régimen que busca subsidiar a usuarios de estratos inferiores para que puedan acceder a SPD de acueducto, alcantarillado, aseo, energía eléctrica, gas y telefonía fija. ${ }^{1}$ A este propósito, la ley dispone la necesidad de clasificar los inmuebles residenciales en máximo seis estratos socioeconómicos: 1) bajo-bajo; 2) bajo; 3 ) medio-bajo; 4) medio; 5) medio-alto; y 6) alto (art. 102). Los usuarios de los estratos más altos ( 5 y 6 ) y los industriales y comerciales deben cancelar un sobrecosto destinado a financiar los pagos de los consumos mínimos de los usuarios de estratos bajos (1, 2 y 3$)$; los cobros diferenciales se ven directamente reflejados en las facturas que reciben los usuarios. ${ }^{2}$

Dicho lo anterior, es posible argüir que las disposiciones normativas sobre la estratificación socioeconómica hacen parte de una política pública orientada a hacer vivir. Michel Foucault $(2000,218)$, al explicar las transformaciones del derecho acaecidas durante el siglo XIX, afirma que ha emergido un nuevo poder: el poder de hacer vivir distinto al derecho del soberano. Según Foucault, "el poder es cada vez menos el derecho de hacer morir [el derecho de la soberanía] y cada vez más el derecho de intervenir para hacer vivir, sobre la manera de vivir y sobre el cómo de la vida" $(2000,224)$. Así pues, la necesidad de garantizar el acceso a los SPD, algunos de ellos imprescindibles para asegurar la vida — en la acepción más embrionaria del término — supone una intervención sobre la misma en aras de mantener a una población, de hacerla vivir $\mathrm{y}$, en ese orden de ideas, es también un proceso biopolítico en la medida en que pone de relieve la vida como centro de la regularización estatal. Así, la $z \bar{o} \bar{e}$ (el hecho de vivir per se) se inserta en la esfera de la polis (Agamben 1998, 13). ${ }^{3}$

En este punto, vale la pena profundizar sobre qué es la vida para entender el propósito de la biopolítica. Si en el marco de los procesos biopolíticos la intervención estatal busca garantizar la vida, ¿qué significa esto exactamente?; ¿qué tipo de variables se asocian con hacer vivir? Sandra Pedraza
(2012) elabora una conceptualización sugestiva al respecto a propósito de las reflexiones sobre el gobierno de la vida en Colombia (99). De acuerdo con el rastreo que hace esta autora de las definiciones contemporáneas de vida (tanto desde una perspectiva biológica como desde las acepciones propuestas por la Real Academia de la Lengua), "gobernar la vida sería gobernar a los seres humanos en lo que va de su nacimiento a su muerte y actuando sobre la unión del alma y el cuerpo" $(2012,99)$. Al margen de las discusiones teleológicas, filosóficas, sociológicas, etc., que implica pensar en el "gobierno del alma", interesa aquí destacar la temporalidad de la vida sustentada en las condiciones biológicas de nacimiento y muerte para saber cuál es el campo de acción de la biopolítica.

Sin embargo, no basta con decir que la vida (en cuanto introducción de la $z \bar{o} e ́$ en la polis), en lo que va del nacimiento a la muerte de un individuo, es el ámbito de interferencia de los mecanismos biopolíticos. Esto podría hacer creer que el margen de maniobra de la biopolítica es meramente biológico. Nada menos cierto. La biopolítica, en tanto manutención de la vida, tiene injerencia en otros campos implicados en el transcurso de la temporalidad mencionada. De acuerdo con los planteamientos de Foucault (2000, 223), la biopolítica apela a determinados mecanismos reguladores para ejercer su poder y optimizar un estado de vida determinado. Como veremos, la instauración de un orden biopolítico configura procesos de orden social y simbólico para la optimización del cómo de la vida, que está más allá de lo meramente biológico.

Para el caso de la estratificación socioeconómica, se interviene en el nivel de la población, no del individuo, lo cual es importante para poder considerarla un proceso biopolítico. No solamente se busca que la población tenga acceso a servicios públicos vitales, sino que también se actúa sobre otros espacios del cómo de la vida. El estrato social es un catalizador que orienta la inversión pública, la implementación de programas sociales (por ejemplo, en materia de vías, salud, saneamiento, educación y recreación), el cobro diferencial del impuesto predial y la formulación de ordenamientos territoriales. ${ }^{4}$ Esto tiene consecuencias en el ordenamiento social por cuanto interfiere no sólo en que la población se mantenga viva (que sus miembros no mueran en tanto puedan acceder a servicios básicos como el agua, por ejemplo), sino en su modo de vivir, de acceder a la esfera pública y de interrelacionarse con otros.

Cierto es que las disposiciones de la Ley 142 de 1994 han encontrado varios óbices para materializarse. Un ejemplo de ello es la puesta en marcha de la estratificación rural, reglamentada solo hasta el año 1999 mediante la Ley 505. ${ }^{5}$ Por otra parte, la revisión de la jurisprudencia tampoco arroja mayores luces sobre la forma concreta de estratificar a las comunidades indígenas. La Ley 142 no posee ninguna disposición explícita sobre el tema. Por otro lado, la Ley 505 dedica un artículo en el que establece que las comunidades indígenas de 
las zonas rurales serán eximidas de estratificación (art. 16), lo cual cambia según lo dispuesto en la Ley 689 de 2001, en la que se demanda un tratamiento especial en la asignación de subsidios para estas comunidades, dadas sus particularidades socioeconómicas y culturales. En dicha ley no hay otras disposiciones sobre el modo de llevar a cabo este tratamiento (art. 102). Por su parte, la Ley 732 de 2002 estipula que hasta tanto el Departamento de Planeación Nacional (DPN), encargado antes que el DANE del diseño de los métodos de estratificación, no suministre la metodología especial de estratificación para las comunidades indígenas, estas serán clasificadas en el estrato 1 (art 2). Esto permite vislumbrar la heterogeneidad en las acciones del gobierno sobre la vida y muestra las carencias observables en los procesos de regulación para determinadas poblaciones. Cabe entonces preguntarse: ¿qué población ha sido, concretamente, objeto de la estratificación socioeconómica, teniendo en cuenta que muchas zonas del país aún no cuentan con cobertura de SPD? Acéptese esta digresión en aras de pensar biopolíticamente en la población como objeto de la intervención política.

Con lo dicho hasta aquí, hay elementos suficientes para analizar de qué manera la estratificación como proceso biopolítico es representada y cuestionada en la novela Los estratos. Esta obra fue escrita en el año 2013 por Juan Cárdenas (autor payanés nacido en 1978), en cuya producción literaria se encuentran otras novelas como Carreras delictivas (2006), Zumbido (2010), Ornamento (2015) y El diablo de las provincias (2018). Los estratos (dividida en tres grandes partes: "Falla", "Sedimento" y "Temblor") narra la historia de un personaje perseguido por un recuerdo de la infancia que aparece paulatinamente en el relato, al principio mediante sensaciones embrionarias y después en una imagen nítida. El recuerdo es el de una circunstancia particular vivida con una nana negra quien había dejado de trabajar en la casa de los padres del protagonista desde que este era un niño por motivos que el lector no puede llegar a conocer con plena certeza, pues son un lugar de indeterminación en la narración.

Aunque en la novela no haya ninguna referencia explícita a un lugar de desarrollo específico, factores como la descripción de los espacios y el habla de los personajes sugieren que el desarrollo de la trama tiene lugar en algún sitio de Colombia, particularmente de la región del Pacífico. Allí, el lector descubre el cómo de la vida de la población cuyos espacios para vivir son descifrados por el narrador, quien presenta sus propias impresiones y ofrece descripciones que van dibujando los lugares por los cuales se mueven él y los otros personajes. Al principio de la novela (Cárdenas 2019, 11-17), el primer sitio descrito es la unidad residencial donde se ubica la vivienda del narrador. Piscina, aspersores en medio del prado, farolas brillantes, senderos de grava roja, árboles y arbustos para ocultar el enrejado dan cuenta de un hábitat aislada, suspendida en un espacio donde los personajes pagan mensualmente por este ambiente. Distinto es el panorama cuando, durante el transcurso de los hechos, el personaje se desplaza por diferentes puntos de la ciudad donde hay vertederos (18-22), casitas de la clase media (58), el centro de una urbe caótica inundada por el tráfico, una chatarrería (81-84), un motel (99-101) y, al final, la selva (135-158). Estos últimos espacios contrastan con la unidad residencial descrita al principio, con la ostentosidad de un complejo residencial minado por personajes que no pueden habitarlo porque no pertenecen a él, tal como ocurre con el vigilante y la empleada de servicio. En últimas, el narrador pinta el contraste entre el modo de vida de las personas según su condición social; esto, acompañado por locutores de radio que informan sobre pueblos inundados por la lluvia y sobre gente desaparecida.

Hay, además, otro espacio: el puerto del recuerdo. En el primer gran segmento de la novela ("Falla"), este espacio se revela tímidamente, pero en los dos segmentos siguientes ("Sedimento" y "Temblor") aparece con fuerza mostrando la podredumbre que lo atraviesa y los lugares sórdidos que lo rodean. El puerto es el lugar de paso hacia la selva, un lugar habitado por gente que vive en casas precarias, carentes de luz eléctrica, cimentadas sobre estacas.

Todos estos lugares ilustran las diferencias espaciales en la forma de vida de las personas. La estratificación socioeconómica, asociada a la caracterización de los lugares donde se habita, gravita en las observaciones del narrador. La movilidad por los espacios le es permitida, casi exclusivamente, al narrador, pero todos los demás (los empleados negros, el chatarrero, los habitantes de la selva) viven en el presidio de espacios que no les permiten moverse espacial ni socialmente, como deja claro la empleada del motel donde el narrador solía reunirse años atrás con su esposa cuando eran novios: "la misma vieja de siempre en el mismo mostrador, una señora negra y muy delgada con unos pómulos arrugados que se le descuelgan por las mejillas" (Cárdenas 2019, 99). La segregación producida por los espacios no es gratuita: permite comprender cómo son los lugares que se habitan y las implicaciones de estos en las relaciones sociales entre los personajes y sus formas de vida. Tal como admite Cárdenas en entrevista con Patricio Pron (2013), en los espacios se juega lo político de la novela.

Pero no solo se trata de que los personajes y los espacios que éstos habitan ilustren las segmentaciones-y segregaciones, como veremos con detalle más adelante - en las cuales se cimienta la estratificación socioeconómica. La obra problematiza veladamente las garantías de esta política presentando personajes a quienes no se hace vivir, sino que se les deja morir. En los barrios pobres (tanto los que aparecen en el recuerdo sobre la nana y en las acciones del presente de la novela) no hay luz eléctrica, ni agua para beber ni, en fin, condiciones dignas para vivir desde un asunto tan elemental como el acceso a servicios públicos. La obra revela que en el gobierno de la vida se ha obviado, en determinados sectores cuyas formas de vida y de interrelacionarse con otros están 
atravesadas por la segregación, el acceso a bienes necesarios para vivir.

Con todo lo dicho, es fácil comprender que las afirmaciones iniciales de este apartado sobre la relación entre estratificación socioeconómica y biopolítica resultan bastante obvias. La labor verdaderamente compleja es aventurar hipótesis sobre el para qué del gobierno de la vida e intentar correlacionarlas con la interpretación de la novela. Particularmente en este trabajo conviene preguntar: ¿para qué hacer vivir mediante una política de estratificación que garantice un acceso a servicios básicos para la subsistencia?; ¿se trata de la ejecución de acciones de un gobierno de la vida preocupado de manera genuina y exclusiva por el bienestar de la población y por la garantía de un buen vivir? Esto último es, justamente, lo que - como se verá-se pone en tela de juicio en Los estratos. Quede definido por ahora, al menos a grandes rasgos, que la política pública de estratificación socioeconómica es un proceso - es también, si se quiere, un mecanismo o dispositivo - de carácter biopolítico, hecho que tiene injerencia en la forma como se constituye no sólo el modo de vida en términos biológicos, sino en las formas de relacionamiento entre los miembros de una población, lo cual se ve representado y cuestionado en la novela de Cárdenas.

\section{La segmentación por estratos: divisiones y segregación}

La estratificación socioeconómica, además de vincularse con la modificación de las formas de vida en términos biológicos, tiene consecuencias en el plano de lo simbólico en tanto configura representaciones sociales con injerencia en las interrelaciones y en el cómo de la vida de los individuos. El estrato social ha pasado de ser una mera caracterización de inmuebles residenciales a erigirse como rótulo de los sujetos, que, en cuanto tal, les confiere atributos y modos determinados de existencia que varían dependiendo de la escala numérica a la que pertenezcan.

La investigación sociológica de Uribe (2018) sobre el caso de Bogotá valida las afirmaciones precedentes. A través de una metodología híbrida entre lo cualitativo y lo cuantitativo, del método de triangulación y de herramientas investigativas como las encuestas y las entrevistas (44-146), la autora analiza las representaciones sociales vinculadas con la noción de estrato. El marco teórico que utiliza (146-147) le permite argüir que tales representaciones involucran procesos de construcción colectiva adheridos a sistemas de significación compartidos con códigos, valores y lógicas clasificatorias. Según Uribe:

[...] la manera particular como en Colombia se habla de estratos sociales tiene que ver con una modalidad de división social que ha tomado una forma particular definida por una política pública. Dado que las mentalidades y las representaciones colectivas toman un tiempo largo para modificarse, la capacidad de esta política pública de impregnar el modo como se piensa el orden social colombiano en tan corto tiempo es asombrosa. $(2008,141)$

Es sugestivo observar que los resultados de la investigación le permiten a la autora mostrar cómo en el caso de los bogotanos "los estratos, como representación social, están relacionados con la diada pobres/ricos. Además de la naturalización de la división social, la asimilación de los estratos a una de las dos categorías es común" (156). Aun a sabiendas de las dificultades metodológicas de generalizar los hallazgos de Uribe a las dinámicas sociales de todo el país, quizás no sea erróneo pensar que lo que ella identifica en el caso de Bogotá puede ser una constante en otras zonas. Téngase en cuenta también que la pertenencia a un estrato modifica de manera precisa las formas de vida de las personas:

La vida de los estratos inferiores transcurre, salvo para el trabajo, en su mayoría, al interior de su mismo estrato. Para ir a la compra de su mercado, al centro hospitalario y al centro escolar, los dos primeros estratos se mueven dentro de su mismo barrio y lo hacen mayoritariamente a pie. Otra cosa muy distinta es la movilidad por la ciudad de los estratos superiores, quienes se movilizan en automóvil particular. Su lugar de trabajo, en promedio, queda cerca de su lugar de residencia; en sus barrios encuentran bancos, supermercados y centros comerciales. Para los estratos 4, 5 y 6 , la ciudad fuera de su zona de movilidad es percibida con desconfianza. (Uribe, Vásquez y Pardo 2006, 89)

En concreto, no parece insensato afirmar que la clasificación por estratos de la política pública de estratificación socioeconómica ha derivado en construcciones del otro que acentúan la segregación. Esto proviene en parte de la imposibilidad de distanciar la pobreza y la riqueza de la pertenencia a un determinado estrato, aunque concretamente el estrato no sea lo mismo que un medidor de ingreso o un rango directamente asociado a la clase social. Es verdad que esta política pública no es un proceso biopolítico sutil, puesto que se ubica dentro de un evidente campo de intervención biopolítica de carácter asistencial para hacer vivir, pero es posible ir más allá e interpretarla como un mecanismo situado en una doble vía: un nivel explícito del hacer vivir (dilucidado en la sección anterior) y un nivel tácito del cómo de la vida, configurado a partir de representaciones sociales que permean las interacciones de la vida cotidiana.

Ahora bien, aunque todas las divisiones raciales podrían considerarse divisiones sociales, no puede decirse que las brechas sociales sean, necesariamente, de carácter racial. Por eso, es pertinente especificar las relaciones entre la segregación racial y la estratificación socioeconómica. Con este 
propósito en mente, es importante definir qué se entiende por "división racial", para lo cual se requiere profundizar en la categoría raza. Esta es una tarea ardua dada la complejidad del término y su asociación analítica con otras categorías como identidad y etnicidad. Aun así, en aras de la síntesis y la claridad explicativa, entiéndase por raza un término de clasificación que retoma rasgos fenotípicos para caracterizar una población determinada.

Peter Wade (2000) explica claramente que la raza, la definición del término y su incidencia histórica no han sido las mismas en todos los tiempos (11-35). Según este autor, un recorrido por la historia de la categoría permite rastrear que entre el siglo XVI y el XVIII el concepto no incluía demarcaciones físicas concretas, como sí ocurría entre los siglos XVIII y XIX en el marco de los discursos ideológicos de la eugenesia. En tanto que, en el siglo XX, con la abolición del racismo científico, la categoría comienza a cuestionarse y a concebirse como una construcción social. Aun cuando este panorama resulta esclarecedor, es importante agregar que hoy la raza sigue asociada con las características fenotípicas sumadas a la descripción del comportamiento de determinados grupos poblacionales. Tal como afirma Todorov (1985), pese a que biológicamente está comprobado que la raza no existe, el racismo sigue siendo un fenómeno completamente vigente (171). Añádase que el racismo es "el nombre dado a un tipo de comportamiento el cual consiste en mostrar desprecio o agresividad sobre la base de las diferencias físicas entre ellos y uno mismo" (Todorov 1985, 171; traducción propia).

En ese sentido, cuando aquí se alude a la segregación racial se hace referencia a la exclusión de grupos raciales (fenómeno asociado con el racismo), definidos así por cuanto sobre ellos operan supuestas diferencias físicas y de comportamiento. La estratificación social tiene relación directa con este fenómeno en órdenes espaciales que se articulan con un orden simbólico. A la segregación espacial asociada con los estratos, se suma la segregación racial. En Colombia, la segregación racial residencial (situación por la cual las poblaciones negras se concentran en lugares de exclusión de los cuales, sobre todo en las grandes urbes, es difícil salir en busca de la movilidad social) es un hecho y "la mayoría de la gente negra en Colombia se concentra en los lugares de las ciudades donde hay más pobreza" (Duarte et al. 2013, 16). Aunque, como vimos, el estrato socioeconómico no es propiamente un indicador de ingresos, no es difícil colegir que la segregación racial residencial opera sobre poblaciones ubicadas en estratos socioeconómicos bajos. En ese sentido, a los problemas en las formas de vida expuestos anteriormente por pertenecer a determinados estratos se suma una segregación de orden racial que acentúa la marginación de grupos poblacionales en el plano de lo simbólico (por las brechas en los imaginarios y representaciones sociales sobre un otro diferente que se excluye) y de lo espacial (por los límites territoriales) que congrega la vida en unos espacios donde resulta muy difícil la movilidad social.
La relación concreta entre estrato y raza es difícil de demarcar dada la complejidad de vincular una categoría social con un concepto derivado de una política pública que termina por tener injerencia en las divisiones no sólo espaciales, sino también simbólicas. Pese a esto, es claro que al problema de la segregación producida por la política pública se suman otros factores de exclusión como la raza. Esto se hace evidente - por supuesto, con las salvedades propias de la ficcionalización - en la construcción narrativa de Los estratos, en la cual se pone de manifiesto que la noción de estrato social produce segregación sin que, claro está, esto signifique que toda segregación representada provenga necesariamente de la estratificación socioeconómica.

Precisamente, en Los estratos se revelan-de nuevo, a través de la mirada del narrador-los problemas de movilidad social mencionados, los sistemas de significación sobre el otro y las lógicas clasificatorias que interfieren en la visión sobre los personajes (categorizados como indios, negros, mulatos) y en la acentuación de la segregación. Pero esto no se muestra de un modo directo. Razón tiene Catalina Holguín (2015, párr. 11) al afirmar que la prosa de Cárdenas se aleja de un modelo realista adherido a la representación en su sentido más básico. Así las cosas, la segregación hacia los negros se dilucida en la evocación del recuerdo sobre la nana (Cárdenas 2019, 85-92) y, muy especialmente, en el pasaje onírico alusivo a los negros haitianos (90-92). Catalina Quesada (2017) interpreta acertadamente esta sección de la novela como una superposición de la trama histórica y política integrada a la irrupción de los movimientos de independencia que tuvieron como protagonistas a los negros. Además, añade que a lo largo de la novela se apunta el "desvanecimiento interesado del elemento negro en el proyecto de construcción de la nación" (74) para dar cuenta de cómo en la obra el negro se muestra relegado de lo que concierne a los espacios de participación en el imaginario de "nación" por cuanto sigue siendo objeto de maltrato y discriminación.

Se puede decir entonces que la segregación social y racial se narra alegóricamente en pasajes oníricos que interfieren en la evocación del recuerdo: el negro, que está muerto antes de estar muerto porque las vejaciones que padece le relegan al espacio de la muerte simbólica (Cárdenas 2019, 91), así como los negros haitianos asesinados que aparecen en el apartado mencionado anteriormente, son los representantes del resto de personajes que aparecen en la narración. Así, en el transcurso de Los estratos, el negro aparece permanentemente en espacios periféricos o marginales: el negro vigilante que no tiene acceso a la piscina de la unidad residencial (16); la niña negra que atiende al narrador en un restaurante precario (120); los negros del hospital psiquiátrico subsidiado por la universidad (quienes, de no ser así, estarían abandonados o muertos) (111); y la nana que se va de la casa de una familia rica por razones nunca expuestas directamente, pero asociadas con alguna vejación padecida por ella (147). 
Es importante anotar que en la novela no sólo hay un interés por destacar el lugar de los personajes en la escala social a partir de los espacios, sino también a través de "la tradición oral, sus ritmos de habla y la teatralidad de su expresión" (Quesada, 2017, 174). En efecto, el juego con el lenguaje, según Cárdenas reconoce reiteradas veces en múltiples entrevistas - recientemente en entrevista con Gina Saraceni (2020) y en encuentros previos con Elvira Navarro (2015), Juan Manuel Espinosa (2015) y Patricio Pron (2013)_, es una clave para comprender la propuesta narrativa del autor y los sentidos que propone en su obra. Aunque estas entrevistas (salvo la realizada por Patricio Pron) no aluden puntualmente a la novela Los estratos, proporcionan apuntes notables para entender que, en esta obra, como en otras de Cárdenas, la apuesta por el uso del lenguaje es importante para demarcar las segmentaciones sociales y raciales a las cuales se ha hecho alusión. Así lo demuestran las voces que aparecen al final de cada apartado (entremezcladas con retazos de noticias y anuncios de periódico), cuya polifonía le permite al lector reconocer la vida del negro al margen del punto de vista imperante del narrador (Cárdenas 2019, 50-51, 102, 158).

Por otra parte, los indios también hacen parte de las poblaciones presentes en la novela, cuyo lugar en la escala social resulta periférico. El propio detective indio que ayuda al narrador a buscar a su nana anuncia, con un tinte irónico en su tono: "Además, de cuándo acá se ha visto que a los indios nos gusten los lugares repletos de cosas, si los indios somos pobres y no tenemos apenas nada, ¿no? Andamos con lo justo" (124). Estas palabras muestran, desde el lugar de enunciación del indio, el reconocimiento del sitio que él y su comunidad ocupan en términos de clase. Sin embargo, el tono irónico que se colige de la aseveración sugiere que esto es así no tanto por la visión que el indio tiene de sí mismo como por la que tienen los otros.

En la novela incluso se señalan las operaciones de exclusión entre los propios grupos marginados. El narrador piensa, a propósito de su viaje selva adentro con el detective indio: "entiendo que un indio normalmente no recibiría semejantes muestras de simpatía en una comunidad de negros. Aquí, sin embargo, parecen sentir devoción por el detective" (144). Esto permite inferir un trato hostil que no se desglosa como otros tópicos a lo largo de los capítulos, pero que denota la complejidad de las interacciones con el otro en el marco de la segregación, incluso entre las propias comunidades segregadas.

De este modo, Los estratos cuestiona y denuncia - a partir de un juego con el lenguaje, no desde una perspectiva meramente panfletaria - la segregación (atravesada por la triada estrato-raza-clase social) en la cual se fijan identidades sobre las que operan mecanismos de exclusión evidentes en la relación entre los espacios y los personajes que interactúan en ellos. Como se ha sugerido previamente, tal segregación interfiere en la posibilidad de movilidad social para los grupos excluidos a cuyos rótulos de clase y raza se suma el de estrato. La novela cuestiona, entonces, el modo en que opera la noción de estrato asociada a la acentuación de una exclusión material y simbólica. Esto conduce a proponer una exégesis contextual de la obra cuya propuesta central se sintetiza en la siguiente sección.

\section{Los estratos: una propuesta de exégesis contextual}

Teniendo en cuenta la trama básica de la novela Los estratos, la cual gira en torno al personaje que evoca el recuerdo de su nana negra y se aventura en la búsqueda de ella en medio de varios problemas personales (incluso psiquiátricos, según él mismo cuenta a lo largo de la obra), la exégesis de esta producción literaria bien podría hacerse tomando como fermento el desentrañamiento de los motivos psicológicos de un narrador-protagonista, perteneciente a una clase social alta, perseguido por un recuerdo que le atormenta, por el rechazo de su esposa y por el declive de su economía porque su empresa está en bancarrota. Podrían dejarse al margen los espacios, el lugar de los personajes y las desigualdades, $\mathrm{y}$ tomar como foco de atención los incidentes acaecidos al narrador. Sin embargo, aquí se considera que este personaje es realmente el subterfugio de una novela sobre la desigualdad, la segregación y las divisiones de los estratos examinadas en las secciones anteriores, lo que no significa que sea una novela realista de denuncia política con un estilo panfletario. Los personajes, sus interrelaciones, los espacios y el uso del lenguaje analizados en los primeros apartados de este artículo permiten justificar lo dicho.

Como se ha demostrado, los negros son personajes centrales. ¿A qué se debe esta particularidad?; ¿son simplemente una parte accesoria del entramado o constituyen un elemento inserto deliberadamente dentro del relato para problematizar la desigualdad? Evidentemente, por todo lo dicho, es plausible inclinarse por la segunda opción. Los ojos del personaje central — desde cuya perspectiva se construye el relato-no son ajenos a la situación de segregación de la ciudad. Esto queda directamente revelado cuando, mientras está en la habitación de un hotel a la espera de poder encontrar a su nana, escucha por la ventana el barullo producido en las cantinas por las canciones de amor y declara que:

Todas las canciones hablan de despecho, de amor no correspondido, de abandono y entonces me descubro pensando que esta gente habla de amor para no decir ni mierda, habla de amor para no decir puta vida, mi casa se hunde, no tengo trabajo, no tengo en qué caerme muerto y en cambio dicen: te prometo que vas a volar con los ángeles, amor mío, te prometo una lluvia de duendecitos en tu rosal. $(2019,118-119)$ 
Entre "esta gente," por supuesto, se cuentan (sobre todo) los negros. Adicionalmente, como hemos visto, el relato de las formas de interacción entre los personajes conforma las representaciones de la división. El personaje central aduce que "si alguien se asomara por la ventana ahora y me viera charlando con el vigilante pensaría que nos estamos emborrachando juntos. Un propietario y el vigilante, un cuadro siniestro que a mí me divierte" $(2019,17)$. He ahí otra muestra de la configuración de la segmentación social acentuada, aún más, por un factor racial presente permanentemente en el desarrollo de la narrativa de la novela. Recuérdese que el vigilante es un negro, lo cual es importante porque marca aún más la distancia entre ambos personajes desde la perspectiva del narrador, blanco y de clase alta, quien hace mofa de ello.

De manera que en Los estratos nada es gratuito. El entramado del relato configura, a través de la alegoría y la polifonía, la segregación. En palabras de Cárdenas durante la entrevista con Patricio Pron, su intención con el libro es construir "una especie de artefacto que sea capaz de ir atravesando todos esos estratos" (2013). Por otro lado, el autor explica que "En Colombia, en sentido literal, existen los estratos. Según el barrio donde vivas perteneces a una clase social y te llegan los impuestos con unos papeles que ponen estrato 1,2 o 3 , en fin, el que sea. Digamos que es una manera de oficializar las castas y es una herramienta de control social" (El Heraldo 2013). Al margen de las imprecisiones de su aclaración sobre la estratificación, interesa subrayar el reconocimiento de la segregación y del control social como elementos que atañen a una política de estratificación socioeconómica junto con lo revelador que resulta que ello se inserte en la novela, puesto que es un indicador del influjo que dicha política ha tenido en diferentes esferas. La obra desbarata el discurso oficial, inserto en una política que aparentemente busca las garantías para hacer vivir, y revela cómo se deja morir a quienes son excluidos de la esfera pública, a quienes se les niega la movilidad.

Sin el ánimo de hacer un análisis literario comparativo, conviene agregar que en la novela Los estratos se identifican varios elementos presentes en otras obras de Cárdenas. En el caso de Ornamento (2015), aunque con una trama completamente distinta, se encuentra una apuesta narrativa similar. Destaca al respecto el apunte de Lombardo (2017), quien arguye sobre Ornamento: "la mirada de soslayo, el interés en los intervalos, las descripciones de los recorridos, el análisis de la metamorfosis del personaje pone en cuestión la función de los objetos, de los cuerpos y de los sujetos que componen un cuerpo social" (123). Guardando las proporciones, esto mismo es aplicable para el caso de Los estratos, obra en la cual los cuerpos que conforman el cuerpo social son objeto de una intervención biopolítica cuyo discurso del hacer vivir se problematiza por cuanto la narración también devela a quiénes se está dejando morir.

En síntesis, aquí se propone una interpretación que parte de una exégesis del contexto como herramienta interpretativa para la novela. Así, se afirma que esta obra literaria subraya el hondo calado que ha tenido la política de estratificación socioeconómica en lo social a través de la representación que un escritor contemporáneo hace a través de ella como material importante para su construcción narrativa. Esta es, a todas luces, una exégesis que abandona deliberadamente una posibilidad interpretativa psicológica que podría enfocarse en un personaje-narrador abrumado por sus preocupaciones personales. Se ha buscado cimentar un análisis contextual que, por todo lo dicho en las secciones precedentes respecto a la estratificación socioeconómica como proceso biopolítico con injerencia en las divisiones sociales y raciales, realiza apuntes para comprender la novela desde los personajes, las relaciones entre ellos, los espacios y el lenguaje. El narrador, supuesto protagonista, es un catalizador que visibiliza, que dibuja ante los ojos del lector, el panorama sombrío de territorios abrumados por las divisiones, por la segregación propia de los estratos.

\section{Corolario}

Todo lo dicho hasta ahora intenta demostrar cómo la estratificación socioeconómica, idiosincrásica de Colombia, es un proceso biopolítico. Además, hay un interés por hacer una breve pesquisa sobre las divisiones sociales procedentes de dicha política pública e interrelacionarlas con las posibilidades interpretativas de una obra literaria contemporánea. Sin embargo, es urgente concluir este análisis subrayando limitaciones susceptibles de convertirse en oportunidades de indagación.

La primera sección establece que la estratificación socioeconómica se orienta a hacer vivir, pero no responde concretamente para qué o con qué propósito, es decir, no ubica metódicamente las intenciones subrepticias de esta política. Para arrojar luces sobre este interrogante es preciso, entre otras cosas, ahondar mejor en el marco en el que emerge la política teniendo en cuenta factores como la apertura económica y las iniciativas globales de focalización del gasto público. Es admisible pensar que la estratificación ha hecho vivir a la fuerza de trabajo de las principales urbes del país, dado que la mayoría de la población estratificada se encuentra en estas zonas. Aun así, haría falta indagar aspectos cuantitativos para justificar esta aserción mediante cifras generalmente no sistematizadas con precisión por parte de las entidades estatales. Al respecto, así como se ahonda en el hacer vivir, también es importante preguntarse más a fondo a quiénes se deja morir y cuáles son las razones por las cuales ello acontece. De forma concomitante, la carencia de una respuesta exhaustiva a estas preguntas también se observa en el análisis propuesto sobre la novela de Cárdenas.

Las secciones II y III también tienen carencias. Por un lado, es preciso hacer una investigación detallada de los efectos de 
la política de la estratificación social para validar la hipótesis de que existen relaciones de causalidad entre esta y la segregación a nivel nacional. Además, es importante profundizar en la relación entre la política de estratificación y la raza con otras categorías asociadas que resultan complejas, tales como identidad y etnicidad.

Finalmente, la propuesta de exégesis sobre la novela de Cárdenas desde el punto de vista aquí explorado (a partir de una interrelación entre la narrativa, la política pública y la biopolítica) bien podría extenderse a otras producciones literarias de este y otros autores que quizás aborden los temas analizados de forma central. Con todo, se espera haber esbozado una posibilidad hermenéutica - no encontrada profusamente en la revisión de la teoría sobre el tema - de la política pública de estratificación socioeconómica como proceso biopolítico y del provecho que tiene como insumo contextual para la interpretación de obras literarias que representan, cuestionan y problematizan las políticas propias del gobierno contemporáneo de la vida. ${ }^{6}$

\section{Obras Citadas}

Agamben, Giorgio. 1998. Homo sacer: el poder soberano y la nuda vida I. Traducido por Antonio Gimeno Cuspinera. Valencia: Pre-textos.

Cárdenas, Juan. 2013. "Los estratos: Juan Cárdenas”. Entrevista por Patricio Pron. Casa de América, marzo 7, 2013. https:// www.youtube.com/watch? $\mathrm{v}=$ ahhNTptR0ck.

--- 2015 . 'Lanzamiento del libro 'Ornamento', de Juan Cárdenas”. Caro y Cuervo TV, mayo 26, 2015. https://www.youtube. com/watch?v=xjwD0KOd6Go.

--- 2015 . Ornamento. Cáceres: Editorial Periférica.

--- 2015 . "Ornamento". Entrevista por Elvira Navarro. Casa de América, febrero 18, 2015. https://www.youtube.com/ watch?v=Um8mTQgDE4Q.

--- 2019. Los estratos. Colombia: Tusquets Editores.

--- 2020. "Literatura hoy desde la BLAA. Entrevista al escritor Juan Cárdenas". Entrevista por Gina Saraceni. Banco de la República, marzo 9, 2020. https://www.youtube.com/watch?v=4U 8Fnk9Gjg.

DANE. 2018. "Estratificación socioeconómica”. Web. Noviembre 15, 2018.

Duarte, Natalia., Sebastián Villamizar., María José Álvarez y César Rodríguez Garavito (Dirs.). La segregación residencial y las condiciones de vida de las ciudades. Bogotá D.C: Anthropos, 2013.

Eslava, Adolfo. 2011. El juego de las políticas públicas: reglas y decisiones sociales. Medellín: Fondo Editorial Universidad EAFIT.

Foucault, Michel. 2000. "Clase del 17 de marzo de 1976”. En Defender la sociedad, 217-237. Buenos Aires: Fondo de Cultura Económica.

Gálvez, Marissa y Rosa Burrola. 2017. "Identidad ciborg en la narrativa de Santiago Roncangliolo y Juan Cárdenas: dicotomías de lo orgánico y lo mecánico en la construcción del cuerpo". Valenciana (20): 137-160. http://www.scielo.org.mx/scielo. php?script=sci arttext\&pid=S200725382017000200137.

Holguín, Catalina. 2015. "La obra de Juan Cárdenas. Distorsiones y malentendidos”. Revista Arcadia, abril 17, 2015. https:// www.revistaarcadia.com/impresa/literatura/articulo/obra-juan-cardenas-escritor/41879/.

Lombardo, Martín. 2017. “Cuerpo y tiempo en Ornamento de Juan Cárdenas”. Antares 9 (17): 108-123.

Ley $N^{o} 142.11$ de julio de 1994. Diario oficial de la República de Colombia. Bogotá D.C. 
Ley $N^{o}$ 505. 29 de junio de 1999. Diario oficial de la República de Colombia. Bogotá D.C.

Ley $N^{o}$ 689. 31 de agosto de 2001. Diario oficial de la República de Colombia. Bogotá D.C.

Ley $N^{o} 732.31$ de enero de 2002. Diario oficial de la República de Colombia. Bogotá D.C.

Mercier, Claire y Bernardo Rocco. 2019. "Cuerpo capital: las prácticas bioartísticas en Ornamento de Juan Cárdenas y La comemadre de Roque Larraquy”. Romance Quarterly 66 (2): 82-90. https://www.academia.edu/39325772/Cuerpo capital_las_pr\%C3\%A1cticas_bioart\%C3\%ADsticas_en_Ornamento_de_Juan_C $\%$ C3\%A1rdenas_y_La_comemadre de Roque Larraquy.

Ordóñez-Matamoros, Gonzalo. 2013. Manual de análisis y diseño de políticas públicas. Bogotá: Universidad Externado de Colombia.

Pedraza, Sandra. 2012. "La disposición del gobierno de la vida: acercamiento a la práctica biopolítica en Colombia". Revista de Estudios Sociales 43: 94-107. https://journals.openedition.org/revestudsoc/7159.

Quesada, Catalina. 2017. "Juan Cárdenas y la otra tradición”. En Escribiendo la nación, habitando España. La narrativa colombiana desde el prisma trasatlántico, editado por Virginia Capote y Ángel Esteban, 167-186. Madrid:

Iberoamericana.

Redacción El Heraldo. 2013. "Juan Cárdenas novela los efectos de la desigualdad en 'Los estratos"”. El Heraldo, marzo 10, 2013. https://www.elheraldo.co/entretenimiento/cultura/juan-cardenas-novela-los-efectos-de-la-desigualdad-en-losestratos-102965.

Santos, Boaventura de Sousa. 2010. Para descolonizar a Occidente: más allá del pensamiento abismal. Buenos Aires: CLACSO.

Todorov, Tzvetan. 1985. "Race, Writing and Culture". En "Race”, Writing and Difference, 11-35. Traducido por Loulou Mack. Chicago and London: University of Chicago.

Uribe, Consuelo., Socorro Vásquez y Camila Pardo. 2006. "Subsidiar y segregar: la política de estratificación y sus efectos sobre la movilidad social en Bogotá". Papel político 11 (1): 69-93. http://www.scielo.org.co/pdf/papel/v11n1/v11n1a04. pdf.

--- 2008. "Estratificación social: de la política pública a la dinámica de segregación social en Bogotá". Universitas Humanistica (65): 139-171. https://revistas.javeriana.edu.co/index.php/univhumanistica/article/view/2245.

Wade, Peter. 2000. Raza y etnicidad en Latinoamérica. Quito: Ediciones Abya-Yala.

\section{Notas}

1. La ley no sólo refiere los mecanismos para subsidiar, también trata otras materias: personas prestadoras de servicios; régimen de actos y contratos de las empresas; entidades de regulación, control y vigilancia para la prestación del servicio; organización y procedimientos administrativos, etc. No obstante, en este documento interesan especialmente las disposiciones del título VI, que trata sobre el régimen tarifario y, concomitantemente, sobre la estratificación socioeconómica.

2. El estrato 4 debe cancelar el costo estándar del préstamo de los servicios. En principio, la ley dispuso porcentajes específicos en los que el sobrecosto que debían pagar los estratos más altos junto con los industriales y comerciales (art. 89, numeral 89.1) era de máximo $20 \%$ en tanto que los subsidios para los estratos 1,2 y 3 eran del 50\%, 40\% y 15\% respectivamente (art. 99 , numeral 99.6). Sin embargo, estas cifras cambian de acuerdo con las disposiciones tarifarias de las Empresas Prestadoras de SPD.

3. Giorgio Agamben $(1998,9)$ explica la teoría de Foucault sobre la biopolítica mediante una reconstrucción terminológica de 
lo que para los griegos significaban las palabras zōé y bíos. La primera se refiere al hecho mismo de vivir (común a todos los seres vivos), mientras que la segunda atañe a una manera de vivir particular de un individuo o grupo. Al plantear que la $z \bar{o} \bar{e}$ se inserta en la polis Agamben (13) vislumbra un núcleo significativo de la biopolítica foucaultiana que él propone corregir o completar en parte apelando a la categoría nuda vida. Sobre este tema véase Agamben, Giorgio. 1998. Homo sacer: el poder soberano y la nuda vida I. Valencia: Pre-textos.

4. Sobre las aplicaciones de la estratificación en esferas distintas a la prestación de SPD véase Departamento Administrativo de Información Estadística. 2018. "Estratificación socioeconómica”. Web. Noviembre 15, 2018.

5. Las metodologías de estratificación difieren según se trate de zonas rurales o urbanas (de hecho, Bogotá tiene una metodología especial que debe realizarse por manzanas). Tal como se estipula en la Ley 505 de 1999, en las zonas rurales y las fincas y viviendas dispersas se debe hacer la estratificación por medio de la capacidad productiva de los predios con base en la Unidad Agrícola Familiar (UAF). Esto no aplica para predios que no se dedican a actividades productivas y para los Centros Poblados Rurales. La implementación de estas disposiciones metodológicas ha sido de difícil concreción.

6. Se han hecho algunas apuestas interpretativas sobre la obra de Cárdenas (sobre todo de la novela Ornamento) en relación con la construcción del cuerpo, la biopolítica e incluso con el posthumanismo. Véase Gálvez, Marissa y Rosa Burrola. 2017. "Identidad ciborg en la narrativa de Santiago Roncangliolo y Juan Cárdenas: dicotomías de lo orgánico y lo mecánico en la construcción del cuerpo". Valenciana (20): 137-160; Mercier, Claire y Bernardo Rocco. 2019. "Cuerpo capital: las prácticas bioartísticas en Ornamento de Juan Cárdenas y La comemadre de Roque Larraquy”. Romance Quarterly 66 (2): 82-90 y Lombardo, Martín. 2017. "Cuerpo y tiempo en Ornamento de Juan Cárdenas." Antares 9 (17): 108-123. Sin embargo, en general no hay una bibliografía profusa que integre la biopolítica como insumo central para la interpretación de la producción literaria de este autor ni, mucho menos, apuestas teóricas que relacionen políticas públicas específicas con un marco de análisis situado entre la biopolítica y la literatura. 